\title{
ENTIDAD CONVOCANTE Y GESTACION DEL CONGRESO
}

\author{
Por el Comité de Dirección de la Escuela \\ de Formación Social de Vigo
}

Con ocasión de preparar las elecciones sindicales de 1975 un grupo de personas realizamos una experiencia educativa de efectos limitados pero positivos, entre 22 trabajadores de los astilleros vigueses, dada la situación sociopolítica del país.

Aquella expetiencia, aparte de sus consecuencias inmediatas, permitió constatar la necesidad de ampliar, profundizar e impulsar de un modo permanente y ordenado una serie de actividades dirigidas a la formación integral de la persona en sus aspectos sociales, políticos, sindicales, económicos, laborales, etc., partiendo de la experiencia y de las condiciones vividas por la clase trabajadora y por el Movimiento Obreto en los momentos actuales.

No se buscaban unos contenidos teóricos abstractos, separados de la realidad y de la vida, sino un conjunto de actividades de educación auténticamente popular. Esta educación surge de una relación entre la práctica o realidad y las interpretaciones sobre la misma y se dirige a un compromiso personal y colectivo de los que participan en ellos.

En dichas actividades un elemento fundamental sería la participación activa, creativa y pluralista de todos: órganos directivos, responsables de cursillos y asistentes a las actividades. La clase trabajadora sería la protagonista de la futura Escuela en una línea autogestionaria.

A la altura de los meses de mayo y junio de 1975 estas ideas van concretándose y encarnándose. Un grupo de trabajadores y profesionales, desde una mentalidad abierta al pluralismo y partiendo de una postura de solidaridad y de la convicción del papel fundamental de la clase trabajadora, se deciden a poner en marcha la realidad de la Escuela de Formación Social de Vigo.

Se establecen contactos entre varias personas, se dialoga, se reflexiona y se clarifican criterios. Al mismo tiempo se pulsa su opinión y su posible respuesta. El resultado fue la formación de una Comisión técnica y gestora, compuesta por siete personas, presididas por un Director, cuyas funciones eran: dar a la Escuela la necesaria organización y estructura para su funcionamiento y programar e iniciar las primeras actividades de la misma.

La primera reunión de la Comisión se realizó el 11 de junio de 1975. A 


\section{POR EL COMITE DE DIRECCION}

partir de dicha reunión y a lo largo de los cursos pasados se han ido definiendo y concretando los objetivos y métodos de la Escuela.

Unos y otros aparecen en la concepción de la Escuela como un Centro de educación popular orientado al desartollo y a la formación integral de la persona, principalmente en las vertientes de la formación social, laboral, política, sindical, económica, etc., para intervenir y actuar, orientando la construcción de nuestra sociedad en un sentido personalista-comunitario. Recogiendo el tico patrimonio del humanismo cristiano.

Las actividades de la Escuela se dirigen fundamentalmente y en primer lugar a la clase trabajadora de Vigo, y en general, a todas aquellas personas interesadas en conocer la tealidad socioeconómica que nos todea y problemas conectados con ella para analizar objetiva y críticamente, y actuar en consecuencia.

De ahí surgen, en un nivel más concreto, las características o tasgos de la Escuela. Son los siguientes:

1. La Escuela no pretende transmitir una mera información, unos contenidos teóricos, sino que busca que el pueblo y especialmente la clase trabajado. ra, adquiera una formación y unos critetios para poder interpretar las situaciones y las estructuras de la realidad social, política, económica, laboral, cultural..., así actuaremos responsablemente para cambiar las estructuras y situaciones que anulan o dificultan la realidad de los hombres y de los grupos sociales.

2. Las actividades de la Escuela se hallan entaizadas en la realidad de Ga. licia, nacionalidad histórica, preocupándose fundamentalmente de los diversos aspectos, problemas y cultura de nuestra sociedad gallega. Como consecuencia de ello, y en cuanto a la lengua, la Escuela en sus actividades utiliza el gallego y el castellano, pero con preferencia del primero como compromiso firme pata su normalización.

3. Ante las diversas interpretaciones, la actitud de la Escuela es crítica, abierta y pluralista. Es decir, no es «partidista», aunque tampoco es indiferente ante las distintas estructuras, regímenes, sistemas, situaciones e ideologías. Nos mantenemos en un espacio concreto de acción, distinto del específico de los partidos o centrales sindicales, precisamente por huestro carácter independiente y objetivo.

4. La Escuela desarrolla su labor en contacto con el pueblo y con las organizaciones y movimientos sociales, políticos y culturales que surgen del pueblo. Por ello, está presente en asociaciones, bartios, parroquias..., y en contacto con sindicatos y partidos, ofreciendo a todos ellos sus servicios.

5. La orientación de la Escuela es autogestionaria, interviniendo todos sus componentes, haciendo lo más asequible posible esa intervención.

6. En sus actividades insiste y potencia los valores sociales de cooperación, solidaridad, participación, compromiso, importancia de lo colectivo...

Asimismo cultiva y defiende los principios democráticos y los derechos de la persona y de los grupos en orden a aproximarnos lo más posible a un modelo de sociedad personal-comunitaria.

7. La valoración de la persona y de su actividad transformadora responde a valores éticos y morales recogidos en la tradición cristiana-católica.

Por otra parte, a partir de dicha reunión del 11 de junio, la Comisión técnica y gestora da paso a los órganos directivos de la Escuela, una vez cumplidos los objetivos de la Comisión. De esta forma se constituyen los siguientes órganos directivos: Comisión Directora, compuesta por 16 personas y Comité Eje- 


\section{ENTIDAD CONVOCANTE Y GESTACION DEL CONGRESO}

cutivo, formado por seis personas. El día 19 de septiembre de 1975 tiene lugar la primera reunión de la Comisión Directora para poner en práctica las primeras actividades y programar el resto del curso. Asimismo en dicha reunión se eligen las personas que desempeñarán los cargos de Secretario, Tesoreto y $\mathrm{Bi}$ bliotecario y se crea el órgano de participación más directa del alumnado y de los asistentes en la marcha y en los objetivos del Centro. Este órgano es la Asamblea.

En septiembre de 1977 se aprobaron los Estatutos definitivos de la Escuela. Estos tecogen la experiencia de estos años de trabajo y sus caractetísticas fundamentales. El Comité de Dirección aumenta hasta sobrepasar las 30 personas, sin contar a los «Asesores».

\section{RESUMEN DE LAS ACTIVIDADES REALIZADAS}

Desde su fundación, el conjunto de actividades es el siguiente:

a) Cursillos, número total: 62 .

Alumnos, número total de participantes en ellos: 4.405 .

b) Charlas o Conferencias, númeto total: 66 .

Participantes en las charlas o conferencias, número total: 3.232 .

c) Mesas Redondas, número total: 21.

Participantes de las Mesas Redondas, número total: 1.715.

d) Asesoría Jurídico-Labotal, númeto total de casos (particulares o colectivos) 162 , (servicio desde 1978-79).

e) Servicio Técnico de Asistente Social, número total de casos atendidos: 132 (servicio desde 1978-79).

f) Alumnos en los cursos de gallego con carácter anual: 124 (servicio desde 1978-79).

g) Biblioteca Popular de Préstamos, utilizada por unas cien personas con carácter reiterativo.

h) Publicaciones, realizadas a nivel del colectivo o de sus miembros en particular. Son numerosas. Destacamos de las primeras la: «Reflexión Etico-Política ante el Referéndum del estatuto Gallego de Autonomia», publicada en la revista «Encrucillada», junio 1980, pgs. 3-100 y que mereció el premio «Fernán. dez Latorre 1980» otorgado por el diario «La Voz de Galicia».

i) El númeto total de alumnos que han pasado por nuestras actividades es de 9.577 .

\section{GESTACION DEL CONGRESO}

En el invierno de 1979 se planteó dentto del Comité de Dirección de la Escuela de Formación Social de Vigo, en entrat en contacto con otras Instituciones de formación social, cívica y sindical, de España, y cuya expetiencia fuese enriquecedora para nuestro caminar, y a las que pudiese interesar también nuestra trayectoria.

Se llegó a esbozar con ellas unas «Jornadas sobre Formación Social y Sindical de España».

$\mathrm{Al}$ año siguiente, un conocimiento mayor del mundo de la formación social 


\section{POR EL COMITE DE DIRECCION}

y sindical del país, nos abrieron la perspectiva de la posibilidad de llevar adelante la realidad de un congreso. Así se comenzó su preparación sobre tres aspectos:

a) Diálogo directo con las Entidades existentes, sobre el interés de llevar adelante un Congreso, temática y objetivos. Completar la lista de Organizaciones.

b) Búsqueda de las personas adecuadas e independientes de siglas políticas o sindicales, para preparar ponencias y subponencias, y la organización general del Congreso.

c) Solicitud de ayudas económicas a distintos otganismos públicos y privados.

En otoño de 1981 estos elementos estaban bastante maduros y se concretó la fecha aproximada del Congreso, buscando el momento más idóneo a nuestro juicio.

Los objetivos se concretan:

1) Conocimiento de las realidades existentes en España en el campo de la educación social, sindical y ciudadana, en un contexto urbano e industrial.

2) Potenciación de esta educación.

3) Concienciación popular de la importancia de una formación de este tipo.

4) Revisión y enriquecimiento de nuestras propias líneas de actuación.

5) Propiciar la coordinación entre los congresistas.

6) Articular desde el Congreso y cara al futuro, plataformas que le den continuidad.

Sin embargo la realización de este Congreso, no sólo por ser el primero, sino también por sus peculiares características, nos siguió planteando una serie de dificultades resueltas pacientemente. El mismo hecho de su lenta preparación fue el factor más importante para poder asumirlas según se iban presentando.

En febrero de 1982 se invita con un programa provisional y un amplio dossier a las Entidades del nivel «A» (Delegados de las Escuelas de Formación Social y de las Escuelas de Formación Sindical de España), que son el núcleo central del Congreso.

Se trataba de abarcar en este nivel, al menos «corporativamente» todo lo que en España existía sobre esta materia.

Como ejemplo de lo que entendemos por «corporativamente», se invita al Servicio de Escuelas de Graduados Sociales (Ministerio de Trabajo) con seis tepresentantes, siendo así que esas Escuelas son en España 12, y los Seminarios de Estudios Sociales, dependientes de ellas, otros 39 más. A la Federación de Escuelas de Asistentes Sociales se les invita con seis representantes, cuando en tealidad son 29. Con las Escuelas Sindicales de las grandes centrales ocurre to mismo, se invita a seis de los organismos de coordinación estatal a nivel de formación, sin embargo por las diversas federaciones o zonas hay también Escuelas o grupos de Formación Sindical.

En junio se convoca oficialmente a los otros niveles:

B) Escuelas Sociales y Sindicales del extranjero (es decir, de Gran Bretaña, Francia, Italia y Portugal).

C) Entidades de Estudio e Investigación Social y Sindical de España y del Extranjero.

D) Personas invitadas a título personal por su cualificación en el campo social y sindical. 
E) Organismos invitados como informadores: medios de comunicación social (T.V., tadio, diarios, revistas...).

F) Miembros de la Presidencia de Honor.

G) Personas e Instituciones interesadas en la temática general del Congreso. La fecha de su celebración se fija del 30 de septiembre al 3 de octubre, y se envían más de dos mil invitaciones personales además de las comunicaciones por los medios de difusión social.

El hecho de invitar a cuatro países del extranjero, se debe a su mayor cercanía en todos los aspectos.

La convocatoria y realidad del «I Congreso de Escuelas de Formación Social y de Escuelas de Formación Sindical de España», ha sido una paciente labor de trabajo llevada a cabo con entusiasmo por los directivos y simpatizantes de la Escuela de Formación Social de Vigo, y ha sido posible por el interés y la acogida de la mayor parte de las Entidades que en el campo de la FormaciónEducación social, sindical y ciudadana, se mueven en España. 